\title{
Caregiver's vision of bedding textiles for elderly
}

\author{
Ann Blaylock ${ }^{1}$, Floriana Constantin ${ }^{1}$, Loredana Ligabue ${ }^{2}$, Licia Bocaletti ${ }^{2}$ Barbora Siroka', Jan Siroky', \\ Tom Wright ${ }^{1}$ and Thomas Bechtold ${ }^{1 *}$
}

\author{
* Correspondence: \\ Thomas.Bechtold@uibk.ac.at \\ ${ }^{1}$ Research Institute of Textile \\ Chemistry and Textile Physics, \\ University of Innsbruck, \\ Hoechsterstrasse 73, A-6850, \\ Dornbirn, Austria \\ Full list of author information is \\ available at the end of the article
}

\begin{abstract}
Senior citizens have specific needs for bedding, clothing, hygiene and medical textiles that are an essential part of their daily life. The "Textiles for Ageing Society (TAGS)" project deals with these specific demands. Caregivers from 6 European countries were asked by means of a semi-structured interview, how bedding textiles can contribute to daily care work. We found that better design could support care work substantially. As examples, in the short term, better design of colour and style should avoid a hospital like appearance, and better control of bed climate will improve a resident's sleep quality. Long term developments are prevented by a number of barriers. Introduction of new bedding concepts is retarded by the fragmented situation between the elderly, care givers, purchasers, manufacturers, researchers, care organisations and politics which needs to be overcome. Caregivers as experts must be heard and their needs must be transformed into more appropriate, cost effective designs of bedding textiles, which can support to the quality of residents in care homes substantially. More intelligent textiles substantially could contribute to support care workers, however their potential has not been exploited yet.
\end{abstract}

Keywords: Ageing; Bedding textiles; Care; Barriers; Qualitative methods; European society

\section{Introduction}

"Ageing is one of the greatest social and economic challenges of the 21st century for European societies. It will affect all European countries and most policy areas. By 2025 more than 20 per cent of Europeans will be 65 or over, with a particularly rapid increase in numbers of over-80s." (Public Health 2014) Moreover, the fertility rate in the European Union is set to decrease over time following the baby-boom generation (1946-1965), but at the same time life expectancy has increased. In 2050, it is expected that 35 per cent of the European population will be 60 and over (Department of Economic and Social Affairs Population Division 2010).

As of the 1st January 2010, from a total European Union population of $501.1 \mathrm{mil}-$ lion, 87.1 million people were aged 65 or over (Active ageing and solidarity between generations, 2011). An ageing society has specific needs for more specifically designed clothes and textiles which must include the socio-cultural environment of the wearer (Twigg 2012; Twigg 2007; Hurd Clarke, Griffin \& Maliha Hurd Clarke et al. 2009).

The value of the European Union market for bed linen in 2008 was $€ 2.6$ billion nonetheless bedding textiles are often seen as low cost commodity (Household and furnishing textiles 2009). The pressure of cost constraints limits the flexibility to

\section{Springer}

(c) 2015 Blaylock; licensee Springer. This is an open access article distributed under the terms of the Creative Commons Attribution License (http://creativecommons.org/licenses/by/4.0), which permits unrestricted use, distribution, and reproduction in any medium, provided the original work is properly credited. 
approach new markets thus production has moved to low-cost countries and as a result, the scientific development in bedding textiles is stagnant and only minimal change in product performance is observed (Meinander \& Varheenmaa 2002).

Quality of sleep determines the level of personal recovery which subsequently influences the emotional state/condition of the resident and also their level of mobility and personal independence (Van Someren 2000). Thermal environment, for example room and bed climate, are also important factors which affect human sleep (Amrit 2007; Okamoto et al. 1998; Okamoto-Mizuno \& Mizuno 2012) hence bedding textiles are an important component to help support the emotional and physical condition of a resident (Zbikowski \& Loker 1992).

Our study addresses that it is of fundamental importance to improve the quality of life for an increasing ageing society. In order to achieve this, manufacturers must produce special products for this category of people. The purpose of this article is to (1) analyse the current use of bedding textiles elderly care facilities, (2) identify the demands of caregivers for improvements, (3) highlight the barriers which prevent the development of better performance low-cost bedding products, (4) give direction in research and development to governing bodies and care providing organisations.

\section{Method}

In 2012 the European Project Textiles for an Ageing Society "TAGS", begun its active work (TAGS-consortium 2014). The aim of the four year programme is to improve and/or innovate products and processes to meet the specific textile needs of a growing sector of ageing people in the European population. The tasks are centred on four main product groups with increasing complexity: bedding textiles for example, bed sheets and blankets; clothing such as everyday garments, underwear and socks; textile products for hygiene and personal care for example, incontinence pads; therapeutic and recreational textiles for instance, bandages, decubitus ulcer prevention, pads, compression stockings and sports clothes.

The TAGS project follows a logical model as shown in Table 1 which demonstrates how input from different sources is hypothesized to lead to short, intermediate and long term outcomes on how bedding textiles with enhanced performance properties could support caregivers and improve the quality of life for the elderly.

TAGS collects information through the following channels: experts, meetings, interviews and brainstorming activities with direct involvement of care givers and residents and semi-structured interviews with care homes and manufacturers to achieve the following objectives:

- Identify new materials, production techniques and technologies based on the demands and requirements formulated by end-users and industry that can improve the performance of textile products for the elderly.

- To assess the scope and boundary conditions for innovation and thus identify barriers which prevent progress.

- Identify standards and specifications for products and formulate recommendations for policy makers and governing bodies. 
Table 1 Logic model guiding the TAGS project

\begin{tabular}{|c|c|}
\hline \multirow[t]{4}{*}{ Inputs } & - Literature analysis. \\
\hline & - Semi-structured interviews with caregivers, elderly, manufacturers. \\
\hline & - Expert input (care givers, researcher, designer, producer). \\
\hline & - Brainstorming activities to identify potentials for innovation. \\
\hline \multirow[t]{4}{*}{ Analysis } & - Evaluation and structuring of information gathered. \\
\hline & - Formulation of summaries in reports. \\
\hline & - Highlight the main findings and refine ideas in expert group meetings. \\
\hline & - Identification of barriers which prevent progress. \\
\hline \multicolumn{2}{|l|}{ Outcomes } \\
\hline \multirow[t]{3}{*}{ Short term } & - Definition of care related requirements for textiles. \\
\hline & - Improved understanding of the functionalities required for textiles in care. \\
\hline & - Understand and reduce the barriers which prevent progress. \\
\hline \multirow{4}{*}{$\begin{array}{l}\text { Medium } \\
\text { term }\end{array}$} & - Initiation of better targeted research and development activities for textiles to be used in care. \\
\hline & - Increase the number of functional textile products available to reduce work load in care. \\
\hline & $\begin{array}{l}\text { - Administer educational tools to better inform the public about the functionality of textiles to } \\
\text { be used in care. }\end{array}$ \\
\hline & $\begin{array}{l}\text { - Increase awareness of the importance of textiles as a product group and how they can assist } \\
\text { and benefit caregivers in daily work. }\end{array}$ \\
\hline \multirow[t]{3}{*}{ Long term } & $\begin{array}{l}\text { - Better definition of needs and function which lead to improved product performance } \\
\text { supporting the idea of independent living and thus improving the quality of life for the elderly. }\end{array}$ \\
\hline & - Support of care workers through use of textiles with better fitted performance \\
\hline & - Reduced costs for care through prolonged period of independent living of elderly. \\
\hline
\end{tabular}

(Parallel tasks: bedding textiles in care, clothing for elderly, hygiene and personal care, therapy and recreation).

\section{Survey instrument}

During the period of 2012 - 2014 we collected data from care giving institutions from: Italy (10 questionnaires from 4 care homes; Austria (15 questionnaires from 5 care homes and 1 hospital); Germany (1 questionnaire from 1 care home); Slovakia (1 questionnaire from 1 care home); and England (1 questionnaire from 1 care home). As a total 26 questionaires were evaluated using approximation of binomial distribution for calculation of the standard deviation given in the Figures.

We designed a written survey instrument to collect information about the different aspects of bedding textiles that were currently in use. We consider what types of material are currently in use; which materials are preferable; what types of functionality would be beneficial to the elderly and/or caregivers and the importance of design features for example; colour, texture, style, design, warmth or easy care.

\section{Interviews}

We assessed each institution by means of a semi-structured interview which allowed the interviewee to evaluate which features in bedding textiles were most important to them. Each interviewee was a selected respondent whose profession was either a care professional or caregiver. The persons that took part in these questionnaires have a total number of 1,977 persons under their care as a whole, across all care homes that participated. 


\section{Results and discussion}

\section{Semi structured interviews - the questionnaires}

Two main groups of elderly were identified dependent on individual living conditions (An Ageing Europe, 2015; Avramov \& Maskova, 2003). The first group of elderly represents active and healthy individuals, who can enjoy an independent and flexible style of living without the daily burden of work. Besides minor health limitations for example, due to blood pressure, diabetes, lowered physical strength or reduced sensory capacity (e.g. impaired sight or hearing), these people lead an active and independent lifestyle. In regards to bedding textiles for this category of elderly, no changes in bedding concept are observed as there are no stringent requirements for adaptation.

The second group of elderly are in a condition in which support through caregivers is necessary. Support is generally provided by family members, professional caregivers or through care homes or hospitals. It is for this group of elderly in which adaptations or new bedding concepts would be valuable in order to support the differing health conditions that come with age, as well as for caregivers in which these developments could help relieve some aspects of their daily care duties.

Characteristics about caregivers that completed the questionnaire and general information about the residents under their care are given in Table 2. As can be seen from the gender analysis, professional care predominantly is provided by women. The age distribution indicates that more than $80 \%$ of the caregivers are aged between 40 years and 60 years. After their children have become independent, reduced family obligations allowed women to return in professional work. An analysis of the professional background of the inverviewd caregivers showed that the major part of persons were certificated caregivers or nurses with long lasting professional experience for more than 15 years.

These results must be understood as a representative case study demonstrating the main aspects of care in relation to the expectations and demands of caregivers in regards to bedding textiles in care homes.

\section{Materials used in bedding textiles}

In regards to the types of material currently used in bedding textiles, as a general trend, all participating care home's responses were similar in that natural material is the preferred type of material for use. A comparison of the presented data collected in the different countries did not show significant differences between the regions. For a detailed statistical analysis a more extensive data basis be would be required, which however

Table 2 Characteristics of interviewed care givers in elderly homes ( $y=$ years)

\begin{tabular}{lll}
\hline Care givers & Number & $\mathbf{2 2}$ \\
\hline Gender & $f / m$ & $22(100 \%) / 0(0 \%)$ \\
Age & $30-39 y$ & $8.70 \%$ \\
& $40-49 y$ & $52.17 \%$ \\
& $50-59 y$ & $34.78 \%$ \\
Certificated care giver/nurse & $60+y$ & $4.35 \%$ \\
Professional experience & & $95.5 \%$ \\
\hline
\end{tabular}


was beyond the scope of the present study. A share of $89 \%$ of the interviewed caregivers recommend natural fibres as material as preferred material for bedding, less than $5 \%$ expect benefits form use of synthetic fibres. A more detailed analysis of the materials currently used indicates a rather conservative use of modern functional materials; $85 \%$ of care home bedding textiles are made from cotton (Figure 1). The other notable category is "Other" which may in fact indicate one of two things: firstly, the lack of understanding about the fibres used or the terminology i.e. carers may have been unfamiliar with "polyamide" and may have been looking for "Nylon". Secondly it was noted that the majority (9 of the 11 responses for "Other") were from the hospital departments this could indicate that the use of more functional materials is thus better recognised in the medical-functional environment of hospitals. (Zhong et al. 2008; Meguro et al. 1992).

An explanation as to why care givers in care homes prefer natural fibres can be attributed to the fact that they are most familiar with this type of material. It is suspected that although carers and elderly people are aware of the types of material being used in existing products in-house, there has been little experimentation with other types of materials.

There is an apparently good correlation between material used in bedding textiles (Figure 1) and the types of fibre which are expected to be advantageous, as $89 \%$ of the caregivers recommended natural fibres and only $5 \%$ expect benefits from use of synthetic fibres. However, there is an obstacle which prevents the development of more advanced products based on new materials and material combinations which stem from the lack of awareness that the appropriate use of synthetic materials could provide additional benefits. Knowledge about the functionalities of synthetic materials has not yet

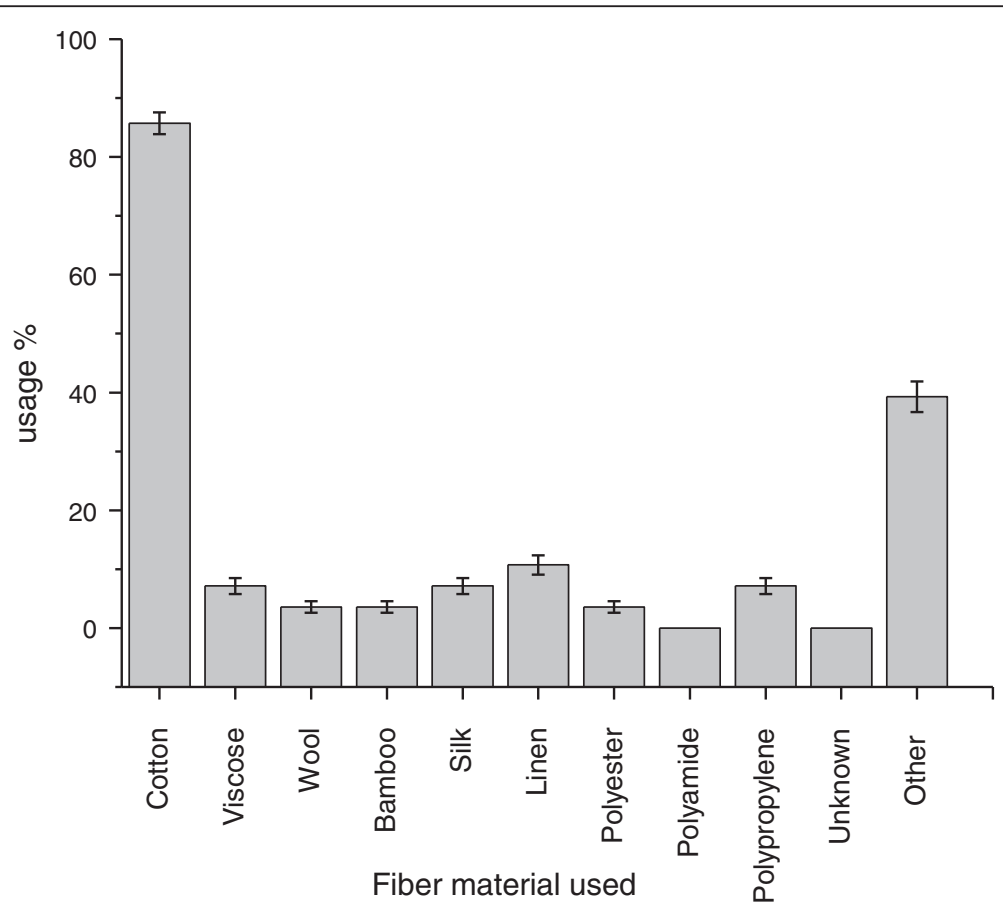

Figure 1 Types of fibres presently used for bedding textiles in care homes (other also includes fibre blends). 
arrived in the field of care giving thus any new developments using fibre blends or new materials are considered with reservation. This obstacle also highlights the need for training about other types of materials and their properties, as well as their benefits and applications for care givers.

The different functionalities currently used in bedding textiles have been analysed (Figure 2). It can be seen that there are clear differences between the desirable functions and actual functions which are prevalent in existing bedding textiles. Among the major functions that are considered relevant, bed climate regulation emerges as an important property. Bed climate is crucial as it relates to: comfort, sweating, perception of dampness which all directly affects the quality of sleep. We would expect contributions of appropriate bedding concepts to lower the frequency of night sweats and other sleep disturbances (Mold, Wooley \& Nagykaldi Mold et al. 2006; Mold, Roberts \& Aboshady Mold et al. 2004; Viera, Bond \& Yates Viera et al. 2003).

Caregivers clearly state that existing products need improvement or have substantial potential to for improvement as potentially available functionalities are currently either not seen or of low effect. Improved hygiene and liquid management properties would also be desirable as developments in this area would benefit those suffering with incontinence and would also contribute towards the prevention of decubitus ulcers and other medical aspects of skin care.

Flame retardancy is an important property which is desired in bedding textiles. The major concern comes from the obvious hazards of smoking in bed, thus clear risk assessments have to be executed to compare actual risks due fire as a result of smoking to more general risks due to low moisture absorbency or hazardous chemicals used for non-flammable finishing.

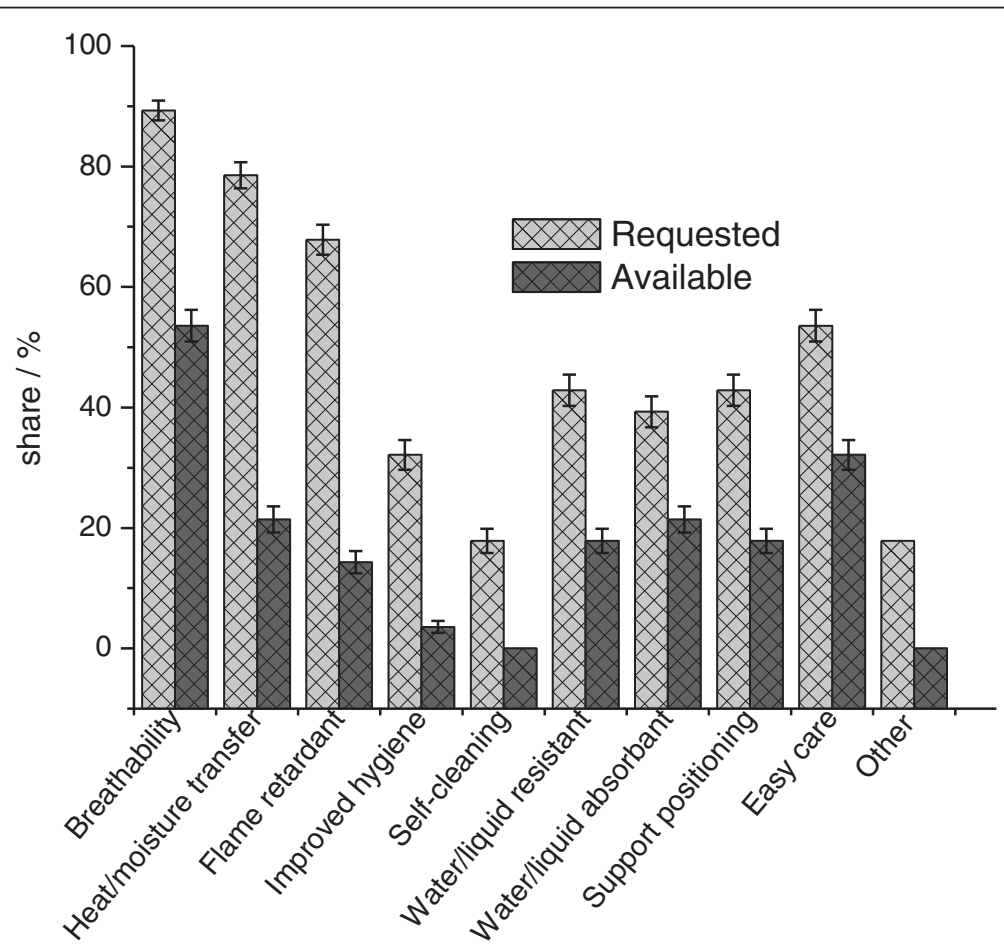

Figure 2 Functionalities that caregivers request for bedding textiles and level of available functions. 
Simple modifications can also result in improvements. In Figure 2 under "Other" a number of requests focused on the colour and design of existing bedding textiles. The use of colour to establish a sense of being at home is preferred to that of a highly sterile hospital appearance which is a known common complaint in care homes.

Caregivers also have concerns about the creases in bed sheets as this causes friction in the bed which can cause bedsores (Zhong et al. 2006).

The use of sensors and electronic devices was also considered as another aspect of bedding textiles. Caregivers would preferentially like such features to be incorporated in order to assist with the aforementioned desired functionalities such as liquid management and hygiene improvement.

\section{Barriers}

Observable progress in product development in bedding textiles for the elderly is limited and the diffusion of scientific results and experiences into practice is unexpectedly slow. Through active discussions with caregivers, manufacturers, designers and product developers some important barriers were identified.

\section{Barrier 1: Beige and grey and not attractive / fashionable}

When support through care giving commences, this particular phase of life is one where the personal circumstance of an individual has to be considered with great sensitivity as this period is often characterised with increasing dependency. Substantial changes in textile concepts can be difficult, and are usually not well received by the elderly person.

This situation is of high relevance for the assessment of textiles used in the later stages of life. Textiles used during the earlier stages of life are kept and continue into the second phase of elderly life. As a result, often inappropriate concepts which have been designed for a younger generation in use and, the overall performance of the textile is no longer suitable for a person in this particular phase of life.

This situation creates a barrier for the introduction of products which are specifically designed for the elderly which must not be associated with infirmity and dependence. Functionality is expected, however design has to be translated into a more suitable style. Instead of buying textiles designed for a younger generation, products for the elderly must exhibit outstanding performance and must be associated with a positive image e.g. experience, elegance, wise, calm-cool. Ideally, such products would also be attractive to a younger audience to create a universal product which has a positive association across all ages.

\section{Barrier 2: The potential of textiles to support care has not yet been realised}

Over the last 50 years bedding textiles have been viewed as a commodity product thus production was mainly optimised to meet the major aspects of design, cost and quality at a competitive level. As an apparently low technology product, the reorganisation of production mainly was executed under the aspects of production costs, which were benchmarked by production in low labour cost countries. Despite the huge market value of several billions of Euros per annual product consumption and the stable consumption, the major share of production capacity for bedding textiles became transferred to developing countries. The high cost pressure limits the flexibility to approach 
new markets, as a result the scientific development in bedding textiles is stagnant and only minimal change in product performance is observed.

Bedding textiles contribute significantly to the overall quality of sleep and thus are of high relevance for the wellness of the elderly in care hence this group of textile products should not be perceived as a low technology or commodity product.

In regards to academia, the reorientation of European academic research in emerging fields of sciences has caused a reduction in interest in the apparently declining field of textiles. This has thus reduced the number of qualified research groups significantly which consequently means that research and development activities in this field, in particular in bedding textiles, are very low compared to the market volume.

\section{Barrier 3: Diffusion of knowledge about the functions of textiles in care is a key-factor}

Depending on the organisational structure, bedding textiles are generally bought by the purchasing department of a care home or by bedding rental companies. These decisions are usually cost and lifetime oriented hence why low technology products, imported from low labour cost countries are favoured. In the majority of cases, the purchasing department has to organise a variety of products from different categories meaning that specific expertise in a certain product range is low and consideration of new specialised products is rare.

The relay of information from care givers into the purchasing department in regards to their needs and demands of bedding textiles is minimal and their involvement in which products to purchase is not usual so the demand for high value higher performing materials is not seen by the manufacturers. As a result, innovative textile producers have to contend with an almost impermeable barrier - the barrier of cost, which is the resultant factor which stems from the lack in knowledge ubiquitous in the purchasing department.

\section{Barrier 4: Caregivers are often not included in early stage product development}

Direct access into care homes in order to appreciate the condition-dependent needs of residents is essential to understand and formulate needs in terms of textile concepts. An integrative approach considering all aspects of bedding including the blanket and filling, as well as nightwear worn by the resident is required to ascertain progress.

The success of new bedding concepts will depend on the availability of supportive information which details the overall benefits and provides cost-analysis with regard to the structure and organisation of care giving facilities.

Direct contact from enterprises with care-homes is in theory, possible, however it is often not welcomed by the care-givers due to:

- A high volume of daily duties.

- Caregivers as a rule, are not involved decision making process when it comes to purchasing in general; no exception for improved bedding concepts.

- The translation of caregiver's demands into textile concepts and products requires specialist knowledge.

- The time scale for the development of a product is rather lengthy.

When the passage of information between caregivers and the purchasing departments in care-homes and hospitals is improved, new concepts will have a realistic chance for successful introduction into the market. 


\section{Barrier 5: How to produce specialised textiles for care?}

The private sector undertakes individual development activities and focuses on processes and product developments. The formation of research consortia is complicated because individual specialisation makes definition of more general research topics difficult. Involvement of care institutions in the development processes is essential however, through their commercial interests and potentially sensitive intellectual property, partnerships with enterprises are difficult to build.

In addition, the evaluation of achievements and transfer of findings into care products is a difficult multi-step process which is rather lengthy which consequently takes a long time to market and thus reduces interest within industry to improve bedding textiles for use in elderly care.

\section{Conclusions}

Our findings suggest that the use of appropriate bedding textiles could substantially support caregivers with their daily work duties. The need for the adaptation of textile products increases with the intensity of care required by the elderly. At present, current bedding textiles are based on the traditional use of material concepts and the benefits of modern functional fibres have not yet arrived in products for care. As representative examples, the development of future bedding textiles should factor in:

- appearance, colour and style - to achieve move care homes from the more hospital like appearance a perception of "living at home".

- climate control - to improve support in temperature regulation reduce accumulation of moisture for better quality of sleep (Avery, Pestle \& Radcliffe, Avery et al. 1985).

- surface properties - to control friction and pressure between skin and bedding (Gerhardt et al., 2009).

- aspects of hygiene and easy maintenance - to support care givers daily routine and to reduce the emotional burden of incontinence (Bloomfield et al., 2011).

At the same time a rigorous control of costs for purchase and maintenance of new products is essential. A clear demand for the development of bedding textiles exists, but there are some limitations which prevent progress:

- There is an undeniable need to develop specialised products specifically for people in elderly care; however the associated image must have positive attributes in order to make such products marketable.

- Bedding textiles are perceived as low cost commodity products, which is a contradiction as they contribute to the overall quality of sleep and wellbeing of residents.

- The diffusion of knowledge between caregivers, research institutions and textile producers is slow due to the fragmented situation and the lack of information exchange and discussion of demands.

- The development of new products requires involvement of care providers who formulate needs and expectations as basis to initiate well targeted product development. 
- The classical business model for bedding textiles is based on the major element of fashion and design thus the price is generally not suitable for products which offer value both to the elderly and care givers.

For caregivers the assessment of products available in the fragmented market is complex and difficult to assess, thus introduction of innovative products is dependent on the individual engagement of a caregiver and wider more general approaches cannot be expected.

There is clear need for innovative concepts however this will require:

- Formation of independent and interdisciplinary platforms of experts which provide assessment of innovations and recommendations for concepts.

- Supportive material which explains the importance of advanced bedding textile concepts for health, quality of sleep and quality of life for the elderly.

- Information tools which enable caregivers, the elderly and textile developers to understand each other's needs and formulate opportunities for new concepts in bedding textiles.

- An understanding that cost is only one element of a much more complex and interlinked decision process to identify the best suited product.

The appearance of a normal life, independence and healthy condition of an elderly person could be supported through improved textile concepts. When developing new concepts manufacturers must be careful not to over integrate the use of sensors as this will indicate disability and a deteriorating health condition which is not a desirable approach.

There is potential to introduce new materials and material combinations into bedding textiles which have increased functionality, however clear concepts must be well designed and prove the ability to contribute to the overall comfort of residents.

The strength of this report includes the findings extracted from direct interviews of care givers in care homes and discussion with enterprises. Through the integration of knowledge from applicants and producers the relevance of bedding textiles for wellbeing of dependent as well as need for substantial improvement is highlighted.

The limitations of this article are that: only information from a small number of stakeholders was considered, thus the findings will not describe the exact situation for every individual case. However, through a general approach the results of our deliberations cover the major aspects which will help support targeted development of improved concepts for bedding textiles used in care. Furthermore, although only a small amount of respondents were reached the wealth of expertise is reflected by the volume of the total residents under their care. 
Author details

'Research Institute of Textile Chemistry and Textile Physics, University of Innsbruck, Hoechsterstrasse 73, A-6850,

Dornbirn, Austria. ${ }^{2}$ Anziani e non solo soc. coop., Via Lenin 55, 41012 Carpi (MO), Italy.

Received: 28 December 2014 Accepted: 27 March 2015

Published online: 12 May 2015

\section{References}

Active ageing and solidarity between generations a statistical portrait of the European Union. (2011). ISBN 978-92-7921507-0, Cat. No KS-EP-11-001-EN-C. Luxembourg: Publications Office of the European Union.

Amrit, UR. (2007). Bedding textiles and their influence on thermal comfort and sleep. AUTEX Research Journal, 8/4, 252-254

An Ageing Europe - Challenges of the European Senior Service Sector. Leonardo da Vinci project no. 134320-LLP-2007DK-LMP. Retreived March 14, 2015, from http://www.adam-europe.eu/prj/3828/prj/WP2\%20Transantional\%20report \%20Challenges\%20ENG.pdf.

Avery, CE, Pestle, RE, \& Radcliffe, PM. (1985). Hypothermia, use of textile items, and the elderly. Cloth Text Res J, 4(1), 53-59. doi:10.1177/0887302X8500400108

Avramov, D, \& Maskova, M. (2003) Active ageing in Europe. Population studies, 41. Directorate General III, - Social Cohesion. Strasbourg Cedex Belgium: Council of Europe Publishing.

Bloomfield, S F, Exner, M, Signorelli, C, Nath, K J \& Scott, E A (2011). The infection risks associated with clothing and household linens in home and everyday life settings, and the role of laundry. International forum on home hygiene. Retrieved March 14, 2015, from http://www.europeantissue.com/wp-content/uploads/The-infection-risksassociated-with-clothing-and-household-linens.pdf.

Gerhardt, JC, Lenz, A, Spencer, ND, Münzer, T, \& Derler, S. (2009). Skin-textile friction and skin elasticity in young and aged persons. Skin Res Technol, 15(3), 288-298. doi:10.1111/j.1600-0846.2009.00363.x.

Household and furnishing textiles - The EU market for bed linen (2009). CBI Market information database October, retrieved Dec. 27. 2014 from http://www.cbi.eu.

Hurd Clarke, L, Griffin, M, \& Maliha, K. (2009). Bat wings, bunions, and turkey wattles: body transgressions and older women's strategic clothing choices. Ageing Soc, 29(5), 709-726.

Meguro, K, Yamaguchi, T, Doi, C, Nakamura, T, Sekizawa, K, \& Sasaki, H. (1992). Bactericidal clothes protect against respiratory infections in the elderly patients. Jpn J Geriatr, 29, 411-415.

Meinander, H, \& Varheenmaa, M. (2002). Clothing and textiles for disabled and elderly people, VTT TIEDOTTEITA - Research Notes, 2143, ISBN 951-38-5898-7. Espoo: VTT Technical Research Centre of Finland.

Mold, JW, Roberts, M, \& Aboshady, HM. (2004). Prevalence and predictors of night sweats, day sweats, and hot flashes in older primary care patients: an OKPRN study. Annals of the Family Medicine, 2, 391-397.

Mold, JW, Wooley, JH, \& Nagykaldi, Z. (2006). Associations between night sweats and other sleep disturbances: an OKPNR study. Annals of the Family Medicine, 4, 423-426.

Okamoto, K, Kudoh, Y, Yokoya, T, \& Okudaira, N. (1998). A survey of bedroom and bed climate of the elderly in a nursing home. J Physiol Anthropol, 17(3), 115-120.

Okamoto-Mizuno, K, \& Mizuno, K. (2012). Effects of thermal environment on sleep and circadian rhythm. J Physiol Anthropol, 31(1), 14

Public Health. European commission, retrieved Dec. 29, 2014 from http://ec.europa.eu/health/ageing/policy/index_en.htm.

TAGS-consortium (2014). Retreived Dec. 29. 2014 from http://www.textilesforageingsociety.eu/.

Twigg, J. (2007). Clothing, age and the body: a critical review. Ageing Soc, 27(2), 285-305.

Twigg, J. (2012). Adjusting the cut: fashion, the body and age on the UK high street. Ageing \& Society, 32(6), 1030-1054

Van Someren, EJW. (2000). Circadian and sleep disturbances in the elderly. Exp Gerontol, 35, 1229-1235.

Viera, AJ, Bond, MM, \& Yates, SW. (2003). Diagnosing night sweats. Am Fam Physician, 67, 1019-1024.

Department of Economic and Social Affairs Population Division. (2010). World population ageing 2009. ST/SEA/SER.A/295, ISBN 978-92-1-151468-1. Sales No. E.10.XIII.5; (p. 13). New York: United Nations.

Zbikowski, P, \& Loker, S. (1992). Clothing and bedding practices and hypothermia awareness of elders: a comparative study. Cloth Text Res J, 10, 30-34.

Zhong, W, Ahmad, A, Xing, MM, Yamada, P, \& Hamel, C. (2008). Impact of textiles on formation and prevention of skin lesions and bedsores. Cutan Ocul Toxicol, 27, 21-28.

Zhong, W, Xing, MM, Pan, N, \& Maibach, HI. (2006). Textiles and human skin, microclimate, cutaneous reactions: an overview. Cutan Ocul Toxicol, 25(1), 23-39.

\section{Submit your manuscript to a SpringerOpen ${ }^{\circ}$} journal and benefit from:

- Convenient online submission

- Rigorous peer review

- Immediate publication on acceptance

- Open access: articles freely available online

- High visibility within the field

- Retaining the copyright to your article

Submit your next manuscript at $>$ springeropen.com 